\title{
Free Vibration Analysis of Fiber Metal Laminate Annular Plate by State-Space Based Differential Quadrature Method
}

\author{
G. H. Rahimi, ${ }^{1}$ M. S. Gazor, ${ }^{1}$ M. Hemmatnezhad, ${ }^{2}$ and H. Toorani ${ }^{1}$ \\ ${ }^{1}$ Department of Mechanical Engineering, Tarbiat Modares University, P.O. Box 14115-143, Tehran, Iran \\ ${ }^{2}$ Faculty of Mechanical Engineering, Takestan Branch, Islamic Azad University, Takestan, Iran \\ Correspondence should be addressed to G. H. Rahimi; rahimi_gh@modares.ac.ir
}

Received 6 May 2013; Revised 30 September 2013; Accepted 2 October 2013; Published 2 January 2014

Academic Editor: Jianqiao Ye

Copyright (C) 2014 G. H. Rahimi et al. This is an open access article distributed under the Creative Commons Attribution License, which permits unrestricted use, distribution, and reproduction in any medium, provided the original work is properly cited.

\begin{abstract}
A three-dimensional elasticity theory by means of a state-space based differential quadrature method is presented for free vibration analysis of fiber metal laminate annular plate. The kinds of composite material and metal layers are considered to be S2-glass and aluminum, respectively. A semianalytical approach which uses state-space in the thickness and differential quadrature in the radial direction is implemented for evaluating the nondimensional natural frequencies of the annular plates. The influences of changes in boundary condition, plate thickness, and lay-up direction on the natural frequencies are studied. A comparison is also made with the numerical results reported by ABAQUS software which shows an excellent agreement.
\end{abstract}

\section{Introduction}

Recently, fiber metal laminates (FML), due to their excellent mechanical properties as well as low density, have gained much attention for aircraft structures. Till now, several research papers have been conducted on the vibrational behavior of these structures. Using the free vibration damping tests, Botelho et al. [1] obtained the elastic and viscous responses for aluminum 2024-T3 alloy, carbon fiber/epoxy composites, carbon fiber/aluminum 2024-T3/epoxy hybrid composites, and glass fiber/aluminum2024-T3/epoxy hybrid composites. They also compared the elastic and viscous responses of these new materials with those of conventional polymer composites. Reyes and Cantwell [2] investigated the quasistatic and impact properties of a novel fiber/metal laminate system based on a tough glass-fiber-reinforced polypropylene. Their testing showed that, by incorporating an interlayer based on a maleic-anhydride modified polypropylene copolymer at the interface between the composite and aluminum layers, one can reach to excellent adhesion properties. Based on the first-order shear deformation theory, Shooshtari and Razavi [3] solved the linear and nonlinear vibrations of FML plate using the multiple time scales method. Khalili et al. [4] studied the dynamic response of
FML cylindrical shells subjected to initial combined axial load and internal pressure. They implemented the Galerkin method for solving the governing equations. They examined the influences of FML parameters and arrived at the point that the FML layup has a significant effect on the natural frequencies of vibration. In recent years, several researchers have implemented the differential quadrature method (DQM) for investigating the free vibration and static analyses of engineering structures. Using the three-dimensional theory of elasticity, Alibeigloo and Shakeri [5] combined the state-space and differential quadrature method (DQM) for investigating the free vibration analysis of crossply laminated cylindrical panels. Based on the theory of elasticity, Li and Shi [6] extended a state-space based DQM for investigating the free vibrational behavior of functionally graded piezoelectric material (FGPM) beam under various boundary conditions. Alibeigloo and Madoliat [7] gave a three-dimensional solution for the static analysis of crossply rectangular plates with integrated surface piezoelectric layers using DQM and the Fourier series approach. Also, the static and free vibration characteristics of anisotropic laminated cylindrical shells have been studied by applying the state-space in conjunction with DQM [8]. Yas and Aragh [9] investigated the free vibration characteristics of rectangular continuous grading 
fiber reinforced (CGFR) plates resting on elastic foundations based on the three-dimensional, linear, and small strain elasticity theory and using DQM.

Nallim and Grossi [10] performed the free transverse vibration analysis of symmetrically laminated solid and annular elliptic and circular plates using Rayleigh-Ritz method. Ovesy and Fazilati [11] applied the finite strip method based upon a Reddy type, third-order shear deformation theory for investing the buckling and free vibrational behavior of thick plates containing internal cutouts. The buckling behavior of laminated composite circular plates having circular holes and subjected to uniform radial load was investigated using the finite element method by Baltaci et al. [12]. They also studied the influences of changes in the hole size, location of the hole, thickness, and boundary conditions on the buckling load. Based on the three-dimensional theory of elasticity and a combination of state-space method and DQM, Nie and Zhong [13] used a semianalytical approach for obtaining the vibration frequencies and dynamic response of functionally graded circular plates. Seifi et al. [14] studied the buckling behavior of composite annular plates under uniform internal and external radial edge loads which have been investigated using energy method. Jodaei et al. [15] used a statespace based DQM to analyze the free vibrational behavior of functionally graded annular plates. They also modeled the plate by artificial neural network for different boundary conditions. Further, the influences of thickness of the annular plate, material property graded index, and circumferential wave number on the nondimensional natural frequencies of the annular plates with different boundary conditions were investigated.

In this paper the free vibrational behavior of FML plate with central hole is investigated based on the theory of elasticity. The plate is considered asymmetric in the tangential direction which means that the displacements, stresses, and strains are functions of the tangential component. A semianalytical method which is a combination of DQM, statespace, and the Fourier series methods is applied for solving the governing equations of motion. By applying DQM in the radial direction, the derivatives in radius direction convert to algebraic expressions. By using the Fourier series in tangential direction, the displacement and stress parameters lose the dependency of the tangential component and the equations will contain only derivatives in the thickness direction. Therefore, state-space method is used for solving the problem and obtaining the natural frequencies. The kinds of composite material and metal layers are considered to be S2-glass and aluminum, respectively. The boundary conditions considered here are clamped-clamped and simply supported-simply supported. The influences of variations in the plate thickness, radius of the plate, layup of composite layers, and radius of the hole on the natural frequencies are investigated. The results obtained show that this method has high precision as well as convergence. The results are compared with those obtained via ABAQUS software. Comparison of the results demonstrates the high accuracy of the solutions and confirms the accuracy of the present results.
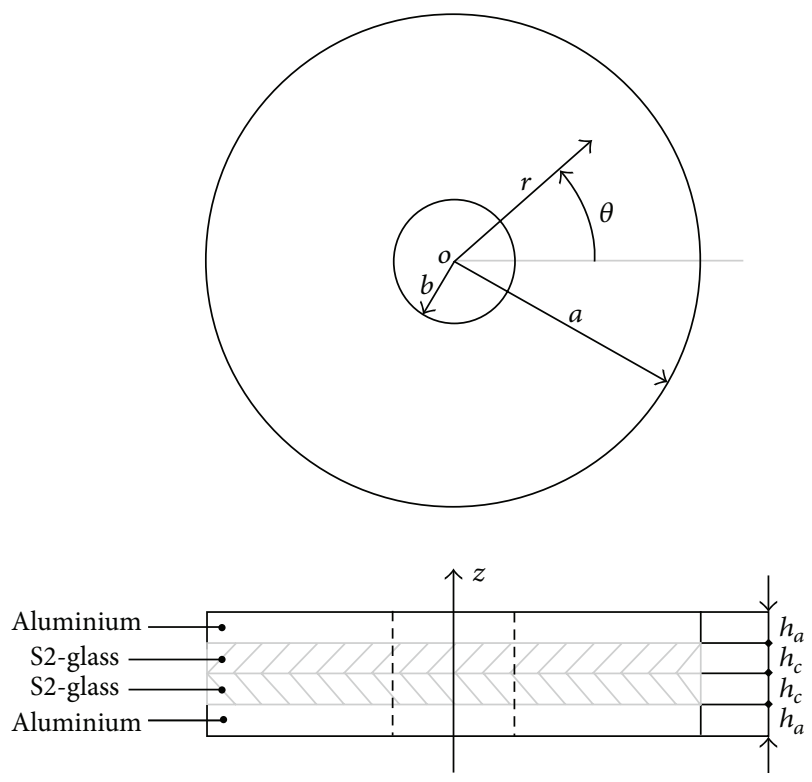

FIGURE 1: Schematic view of a circular fiber metal laminate plate with a central hole.

\section{Basic Equations}

Figure 1 depicts the schematic view of a circular fiber metal laminate plate with a central hole. $a$ stands for the outer radius of the plate and $b$ is the hole radius. The plate is composed of four layers with two T2024 aluminum plates on the top and the bottom and two S2-glass inner layers. Based on the elasticity theory, the governing equations of motion in polar coordinates can be written as

$$
\begin{gathered}
\frac{\partial \sigma_{r}}{\partial r}+\frac{1}{r} \frac{\partial \tau_{r \theta}}{\partial \theta}+\frac{\partial \tau_{r z}}{\partial z}+\frac{\sigma_{r}-\sigma_{\theta}}{r}=\rho \frac{\partial^{2} u_{r}}{\partial t^{2}} \\
\frac{\partial \tau_{r \theta}}{\partial r}+\frac{1}{r} \frac{\partial \sigma_{\theta}}{\partial \theta}+\frac{\partial \tau_{\theta z}}{\partial z}+\frac{2 \tau_{r \theta}}{r}=\rho \frac{\partial^{2} u_{\theta}}{\partial t^{2}} \\
\frac{\partial \tau_{r z}}{\partial r}+\frac{1}{r} \frac{\partial \tau_{\theta z}}{\partial \theta}+\frac{\partial \sigma_{z}}{\partial z}+\frac{\tau_{r z}}{r}=\rho \frac{\partial^{2} u_{z}}{\partial t^{2}}
\end{gathered}
$$

where $\sigma_{r}, \sigma_{\theta}$, and $\sigma_{z}$ are the normal stresses in the radial, tangential, and thickness directions, respectively, $\tau_{r \theta}, \tau_{r z}$, and $\tau_{\theta z}$ are the shear stresses, and $u_{r}, u_{\theta}$, and $u_{z}$ describe the displacement components along radial, tangential, and thickness directions, respectively. The strain-displacement relations are given as

$$
\begin{gathered}
\varepsilon_{r}=\frac{\partial u_{r}}{\partial r}, \quad \gamma_{r \theta}=\frac{1}{r} \frac{\partial u_{r}}{\partial \theta}+\frac{\partial u_{\theta}}{\partial r}-\frac{u_{\theta}}{r}, \\
\varepsilon_{\theta}=\frac{u_{r}}{r}+\frac{1}{r} \frac{\partial u_{\theta}}{\partial \theta}, \quad \gamma_{r z}=\frac{\partial u_{r}}{\partial z}+\frac{\partial u_{z}}{\partial r}, \\
\varepsilon_{r}=\frac{\partial u_{z}}{\partial z}, \quad \gamma_{\theta z}=\frac{\partial u_{\theta}}{\partial z}+\frac{1}{r} \frac{\partial u_{z}}{\partial \theta} .
\end{gathered}
$$

For a linear elastic material, the structural relationship between stress and strain is given as

$$
\sigma_{i j}=C_{i j k l} \varepsilon_{k l} \text {, }
$$


which can be written in the matrix form for the polar system as the following [16]:

$$
\left[\begin{array}{c}
\sigma_{r} \\
\sigma_{\theta} \\
\sigma_{z} \\
\tau_{r \theta} \\
\tau_{r z} \\
\tau_{\theta z}
\end{array}\right]=\left[\begin{array}{cccccc}
Q_{11} & Q_{12} & Q_{13} & Q_{14} & 0 & 0 \\
Q_{12} & Q_{22} & Q_{23} & Q_{24} & 0 & 0 \\
Q_{13} & Q_{23} & Q_{33} & Q_{34} & 0 & 0 \\
Q_{14} & Q_{24} & Q_{34} & Q_{44} & 0 & 0 \\
0 & 0 & 0 & 0 & Q_{55} & Q_{56} \\
0 & 0 & 0 & 0 & Q_{56} & Q_{66}
\end{array}\right]\left[\begin{array}{c}
\varepsilon_{r} \\
\varepsilon_{\theta} \\
\varepsilon_{z} \\
\gamma_{r \theta} \\
\gamma_{r z} \\
\gamma_{\theta z}
\end{array}\right],
$$

where $Q_{i j}$ are the plane stress-reduced stiffnesses for the composite material and their values as a function of material properties and fiber angle are given in Appendix A.

\section{Boundary Conditions}

In the present work two kinds of boundary conditions are considered for the annular plate. The clamped-clamped boundary condition considers the plate around the hole and the outer radius to be fixed. These end conditions are demonstrated by the following equation:

$$
u_{r}=u_{\theta}=u_{z}=0 \quad \text { at } r=a, b .
$$

Another boundary condition considered here is a kind of simple-simple boundary condition. In this kind of boundary condition, the plate is assumed to move freely along the radius direction, whereas in two other directions it is considered to be fixed. This can be stated through the following:

$$
\sigma_{r}=u_{\theta}=u_{z}=0 \quad \text { at } r=a, b .
$$

Also, it should be noted that these end conditions are even along the thickness at the ends.

\section{Solution Method}

The displacement components can be assumed in the following forms which simultaneously satisfy the equilibrium equations and the boundary conditions [15]:

$$
\begin{aligned}
& u_{r}(r, \theta, z, t)=\sum_{m=0}^{\infty} \widehat{u}_{r}(r, z) \cos (m \theta) e^{i \omega t}, \\
& u_{\theta}(r, \theta, z, t)=\sum_{m=0}^{\infty} \widehat{u}_{\theta}(r, z) \sin (m \theta) e^{i \omega t}, \\
& u_{z}(r, \theta, z, t)=\sum_{m=0}^{\infty} \widehat{u}_{z}(r, z) \sin (m \theta) e^{i \omega t} .
\end{aligned}
$$

Also, the stress components can be assumed as

$$
\begin{aligned}
& \sigma_{r}(r, \theta, z, t)=\sum_{m=0}^{\infty} \widehat{\sigma}_{r}(r, z) \cos (m \theta) e^{i \omega t}, \\
& \sigma_{\theta}(r, \theta, z, t)=\sum_{m=0}^{\infty} \widehat{\sigma}_{\theta}(r, z) \cos (m \theta) e^{i \omega t}, \\
& \sigma_{z}(r, \theta, z, t)=\sum_{m=0}^{\infty} \widehat{\sigma}_{z}(r, z) \cos (m \theta) e^{i \omega t},
\end{aligned}
$$

$$
\begin{aligned}
& \tau_{\theta z}(r, \theta, z, t)=\sum_{m=0}^{\infty} \widehat{\tau}_{\theta z}(r, z) \sin (m \theta) e^{i \omega t}, \\
& \tau_{r z}(r, \theta, z, t)=\sum_{m=0}^{\infty} \widehat{\tau}_{r z}(r, z) \cos (m \theta) e^{i \omega t}, \\
& \tau_{r \theta}(r, \theta, z, t)=\sum_{m=0}^{\infty} \widehat{\tau}_{r \theta}(r, z) \sin (m \theta) e^{i \omega t},
\end{aligned}
$$

in which $m=0,1,2, \ldots, \infty$. In this analysis, $m=0$ associated with the axisymmetric vibration gives the first mode of vibration and $m=1$ and $m=2$ present the first and second modes of vibration, respectively. Also, $\omega$ denotes the natural frequency of the plate. Introducing the following dimensionless parameters:

$$
\begin{gathered}
\bar{z}=\frac{z}{h}, \quad \bar{r}=\frac{r}{a}, \quad \Omega=\omega h \sqrt{\frac{\rho_{a}}{Q_{11 a}}}, \\
\left(\bar{u}_{r}, \bar{u}_{\theta}, \bar{u}_{z}\right)=\frac{\left(\widehat{u}_{r}, \widehat{u}_{\theta}, \widehat{u}_{z}\right)}{h}, \quad \bar{Q}_{i j}=\frac{Q_{i j}}{Q_{11 a}}, \\
\left(\bar{\sigma}_{r}, \bar{\sigma}_{\theta}, \bar{\sigma}_{z}, \bar{\tau}_{r \theta}, \bar{\tau}_{r z}, \bar{\tau}_{\theta z}\right)=\frac{\left(\widehat{\sigma}_{r}, \widehat{\sigma}_{\theta}, \widehat{\sigma}_{z}, \widehat{\tau}_{r \theta}, \widehat{\tau}_{r z}, \widehat{\tau}_{\theta z}\right)}{Q_{11 a}} .
\end{gathered}
$$

Equation (1) can be rewritten in the following form:

$$
\begin{gathered}
\frac{1}{a} \frac{\partial \bar{\sigma}_{r}}{\partial \bar{r}}+\frac{m}{a} \frac{\bar{\tau}_{r \theta}}{\bar{r}}+\frac{1}{h} \frac{\partial \bar{\tau}_{r z}}{\partial \bar{z}}+\frac{1}{a}\left(\frac{\bar{\sigma}_{r}-\bar{\sigma}_{\theta}}{\bar{r}}\right)=-\frac{\rho_{i}}{\rho_{a}} \frac{\Omega^{2}}{h} \bar{u}_{r}, \\
\frac{1}{a} \frac{\partial \bar{\tau}_{r \theta}}{\partial \bar{r}}-\frac{m}{a} \frac{\bar{\sigma}_{\theta}}{\bar{r}}+\frac{1}{h} \frac{\partial \bar{\tau}_{\theta z}}{\partial \bar{z}}+\frac{2}{a} \frac{\bar{\tau}_{r \theta}}{\bar{r}}=-\frac{\rho_{i}}{\rho_{a}} \frac{\Omega^{2}}{h} \bar{u}_{\theta}, \\
\frac{1}{a} \frac{\partial \bar{\tau}_{r z}}{\partial \bar{r}}+\frac{m}{a} \frac{\bar{\tau}_{\theta z}}{\bar{r}}+\frac{1}{h} \frac{\partial \bar{\sigma}_{z}}{\partial \bar{z}}+\frac{1}{a} \frac{\bar{\tau}_{r z}}{\bar{r}}=-\frac{\rho_{i}}{\rho_{a}} \frac{\Omega^{2}}{h} \bar{u}_{z},
\end{gathered}
$$

where $\rho_{a}$ is the density of aluminum, $Q_{11 a}$ is the first element of the stiffness matrix for aluminum, and $h$ is the total thickness of the plate. In terms of the above dimensionless parameters, the strain components can be reformed as

$$
\begin{gathered}
\bar{\varepsilon}_{r}=\frac{h}{a} \frac{\partial \bar{u}_{r}}{\partial \bar{r}}, \quad \bar{\gamma}_{r \theta}=-\frac{m h}{a} \frac{\bar{u}_{r}}{\bar{r}}+\frac{h}{a} \frac{\partial \bar{u}_{\theta}}{\partial \bar{r}}-\frac{h}{a} \frac{\bar{u}_{\theta}}{\bar{r}}, \\
\bar{\varepsilon}_{\theta}=\frac{h}{a} \frac{\bar{u}_{r}}{\bar{r}}+\frac{m h}{a} \frac{\bar{u}_{\theta}}{\bar{r}}, \quad \bar{\gamma}_{r z}=\frac{\partial \bar{u}_{r}}{\partial \bar{z}}+\frac{h}{a} \frac{\partial \bar{u}_{z}}{\partial \bar{r}}, \\
\bar{\varepsilon}_{z}=\frac{\partial \bar{u}_{z}}{\partial \bar{z}}, \quad \bar{\gamma}_{\theta z}=\frac{\partial \bar{u}_{\theta}}{\partial \bar{z}}-\frac{m h}{a} \frac{\bar{u}_{z}}{\bar{r}} .
\end{gathered}
$$

Applying the method of the Fourier series and separation of components of displacement and stress at the parameters, these parameters become a function of the thickness and radius. The differential governing equations for vibration analysis of plate has three equations with two variables. To solve these equations, there are different ways but one of the best as well as effective ways is the combination of differential quadrature and state-space methods. This semianalytical approach has a high rate of convergence. 


\section{Differential Quadrature Method (DQM)}

In order to solve the governing differential equations of motion, DQM is applied along the radius direction. Thus, the expressions containing the first and second order derivatives of the displacements are replaced by differential quadrature functions with certain amount of points. For a circular plate of radius $a$, containing a central hole of radius $b$, the selected points in the differential quadrature method are chosen as

$$
r_{i}=\frac{a-b}{2}\left(1-\cos \left(\frac{i-1}{N-1} \pi\right)\right)+b, \quad(i=1, \ldots, N) .
$$

Based on DQM, the $n$ th-order partial derivative of a continuous function as $f(r, z)$ with respect to $r$ at a given point $r_{i}$ is approximated by a linear summation of weighting function values at all points in the domain of $r$ as

$$
\begin{array}{r}
\frac{\partial^{n} f\left(r_{i}, z\right)}{\partial r^{n}}=\sum_{j=1}^{N} g_{i j}^{(n)} f\left(r_{i}, z\right), \\
(i=1, \ldots, N, n=1, \ldots, N-1),
\end{array}
$$

where $N$ is the number of sample points and $g_{i j}^{(n)}$ are the weighting coefficients related to $r_{i}$ defined as

$$
g_{i j}^{(1)}=\frac{M\left(r_{i}\right)}{\left(r_{i}-r_{j}\right)}, \quad i, j=1, \ldots, N(i \neq j),
$$

in which

$$
M\left(r_{i}\right)=\prod_{j=i, i \neq j}^{N}\left(r_{i}-r_{j}\right), \quad g_{i i}^{(1)}=-\sum_{j=1, i \neq j}^{N} g_{i j}^{(1)} .
$$

For higher order derivatives, the values of weighting functions can be obtained from the following formula:

$$
\begin{array}{r}
g_{i j}^{(n)}=-\sum n\left(g_{i j}^{(n-1)} g_{i j}^{(1)}-\frac{g_{i j}^{(n-1)}}{r_{i}-r_{j}}\right), \\
i, j=1, \ldots, N, \quad i \neq j .
\end{array}
$$

\section{State-Space Equations Derivation}

Using (4)-(10) and (11) and applying DQM as proposed in this equations, the state-space equations for the $i$ th sample point can be derived as [5]

$$
\begin{gathered}
\frac{d \bar{\sigma}_{z i}}{d \bar{z}}=-\frac{\rho_{i}}{\rho_{a}} \Omega^{2} \bar{u}_{z i}-\frac{h}{a} \sum_{j=1}^{N} g_{i j}^{(1)} \bar{\tau}_{r z j}-\frac{m h}{a} \frac{\bar{\tau}_{\theta z i}}{\bar{r}_{i}}-\frac{h}{a} \frac{\bar{\tau}_{r z i}}{\bar{r}_{i}}, \\
\frac{d \bar{u}_{r i}}{d \bar{z}}=-\frac{h}{a} \sum_{j=1}^{N} g_{i j}^{(1)} \bar{u}_{z j}+\frac{1}{\bar{Q}_{55}} \bar{\tau}_{r z i}, \\
\frac{d \bar{u}_{\theta i}}{d \bar{z}}=\frac{m h}{a} \frac{\bar{u}_{z i}}{\bar{r}_{i}}+\frac{1}{\bar{Q}_{55}} \bar{\tau}_{\theta z i}, \\
\frac{d \bar{u}_{z i}}{d \bar{z}}=\frac{\bar{\sigma}_{z i}}{\bar{Q}_{33}}-\frac{\bar{Q}_{13}}{\bar{Q}_{33}} \frac{h}{a} \sum_{j=1}^{N} g_{i j}^{(1)} \bar{u}_{r j}-\frac{\bar{Q}_{13}}{\bar{Q}_{33}} \frac{h}{a} \frac{\bar{u}_{r i}}{\bar{r}_{i}}-\frac{m h}{a} \frac{\bar{u}_{\theta i}}{\bar{r}_{i}},
\end{gathered}
$$

$$
\begin{aligned}
& \frac{d \bar{\tau}_{r z i}}{d \bar{z}}=-\frac{\bar{Q}_{13}}{\bar{Q}_{33}} \frac{h}{a} \sum_{j=1}^{N} g_{i j}^{(1)} \bar{\sigma}_{z j}+\frac{h}{a}\left(\bar{Q}_{23}-\bar{Q}_{13}\right) \frac{\bar{\sigma}_{z i}}{\bar{Q}_{33}} \\
& -\frac{h^{2}}{a^{2}}\left(\bar{Q}_{11}-\frac{\bar{Q}_{13}^{2}}{\bar{Q}_{33}}\right) \sum_{j=1}^{N} g_{i j}^{(2)} \bar{u}_{r j} \\
& +\frac{h^{2}}{a^{2}}\left(-\bar{Q}_{11}+\frac{\bar{Q}_{13}^{2}}{\bar{Q}_{33}}\right) \frac{1}{\bar{r}_{i}} \sum_{j=1}^{N} g_{i j}^{(1)} \bar{u}_{r j} \\
& +\frac{h^{2}}{a^{2}}\left(\bar{Q}_{22}-\frac{\bar{Q}_{23}^{2}}{\bar{Q}_{33}}+m^{2} \bar{Q}_{44}\right) \frac{\bar{u}_{r i}}{\bar{r}_{i}^{2}} \\
& -\frac{m h^{2}}{a^{2}}\left(\bar{Q}_{12}-\frac{\bar{Q}_{13} \bar{Q}_{23}}{\bar{Q}_{33}}+\bar{Q}_{44}\right) \frac{1}{\bar{r}_{i}} \sum_{j=1}^{N} g_{i j}^{(1)} \bar{u}_{\theta j} \\
& +\frac{m h^{2}}{a^{2}}\left(\bar{Q}_{22}-\frac{\bar{Q}_{23}^{2}}{\bar{Q}_{33}}+\bar{Q}_{44}\right) \frac{\bar{u}_{\theta i}}{\bar{r}_{i}^{2}}-\frac{\rho_{i}}{\rho_{a}} \Omega^{2} \bar{u}_{r i}, \\
& \frac{d \bar{\tau}_{\theta z i}}{d \bar{z}}=\frac{\bar{Q}_{23}}{\bar{Q}_{33}} \frac{m h}{a} \frac{\bar{\sigma}_{z i}}{\bar{r}_{i}}+\frac{m h^{2}}{a^{2}}\left(\bar{Q}_{12}-\frac{\bar{Q}_{13} \bar{Q}_{23}}{\bar{Q}_{33}}+\bar{Q}_{44}\right) \\
& \times \frac{1}{\bar{r}_{i}} \sum_{j=1}^{N} g_{i j}^{(1)} \bar{u}_{r j}+\frac{m h^{2}}{a^{2}}\left(\bar{Q}_{22}-\frac{\bar{Q}_{13} \bar{Q}_{23}}{\bar{Q}_{33}}+\bar{Q}_{44}\right) \frac{\bar{u}_{r i}}{\bar{r}_{i}^{2}} \\
& -\frac{h^{2}}{a^{2}} \bar{Q}_{44} \sum_{j=1}^{N} g_{i j}^{(2)} \bar{u}_{\theta j}-\frac{h^{2}}{a^{2}} \bar{Q}_{44} \frac{1}{\bar{r}_{i}} \sum_{j=1}^{N} g_{i j}^{(1)} \bar{u}_{\theta j} \\
& +\frac{h^{2}}{a^{2}}\left(m^{2}\left(\bar{Q}_{22}-\frac{\bar{Q}_{23}^{2}}{\bar{Q}_{33}}\right)+\bar{Q}_{44}\right) \frac{\bar{u}_{\theta i}}{\bar{r}_{i}^{2}}-\frac{\rho_{i}}{\rho_{a}} \Omega^{2} \bar{u}_{r i} .
\end{aligned}
$$

The above six equations are the state-space equations which must be solved to obtain the natural frequencies of the plate. After applying the method of Fourier series and DQM, the derivatives along the tangential and radial directions are removed from the final equation and only the first-order derivatives with respect to thickness will remain.

The state-space equations can be found as below

$$
\frac{d}{d \bar{z}} \delta(\bar{z})=M^{k} \delta(\bar{z})
$$

where

$$
\delta(\bar{z})=\left[\left[\bar{\sigma}_{z i}\right]\left[\bar{u}_{r i}\right]\left[u_{\theta i}\right]\left[u_{z i}\right]\left[\bar{\tau}_{r z i}\right]\left[\bar{\tau}_{\theta z i}\right]\right]^{T} .
$$

In (22),

$$
\left[\bar{\sigma}_{z i}\right]=\left[\bar{\sigma}_{z 1} \cdots \bar{\sigma}_{z N}\right]^{T}, \quad\left[\bar{u}_{r i}\right]=\left[\bar{u}_{r 1} \cdots \bar{u}_{r N}\right]^{T}, \ldots
$$

The above equations which form a system of ordinary differential equations can be solved to give

$$
\delta(z)=\exp (M z) \delta(z=0)
$$




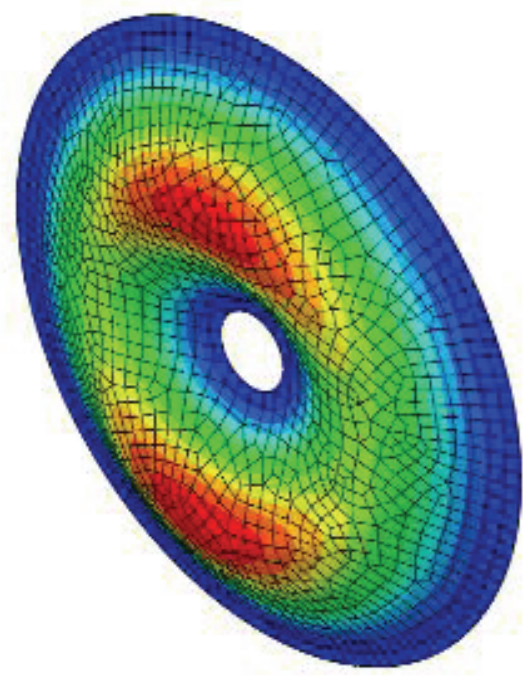

(a)

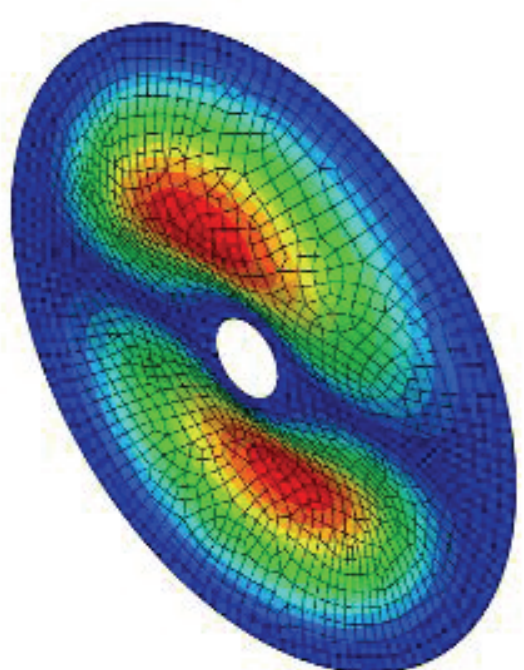

(b)

FIGURE 2: Mode shapes associated with (a) first and (b) second modes of vibration of an annular plate.

in which $\delta(z=0)$ is the state-space vector at the bottom of the plate [5]. Using this equation, the stress and displacement components in the state-space vectors are extracted in each point in the thickness direction and the other components of stress can also be calculated. Matrix $M$ is different for each boundary condition and it is given in Appendix B.

The state-space equations for each layer are written separately. Therefore, for a laminated plate, these equations are combined based on the following relation:

$$
\begin{gathered}
\delta\left(z=h_{T}\right)=\prod_{k=n}^{1} \exp \left(M h^{k}\right) \delta(0), \\
T=\prod_{k=n}^{1} \exp \left(M h^{k}\right) .
\end{gathered}
$$

Expanding the previous equation in the matrix form, we arrive at the following state-space equations for fiber metal laminate as

$$
\left[\begin{array}{l}
{\left[\bar{\sigma}_{z i}\right]} \\
{\left[\bar{u}_{r i}\right]} \\
{\left[u_{\theta i}\right]} \\
{\left[u_{z i}\right]} \\
{\left[\bar{\tau}_{r z i}\right]} \\
{\left[\bar{\tau}_{\theta z i}\right]}
\end{array}\right]_{z=h_{T}}=\left[\begin{array}{llllll}
T_{11} & T_{12} & T_{13} & T_{14} & T_{15} & T_{16} \\
T_{21} & T_{22} & T_{23} & T_{24} & T_{25} & T_{26} \\
T_{31} & T_{32} & T_{33} & T_{33} & T_{35} & T_{36} \\
T_{41} & T_{42} & T_{43} & T_{44} & T_{45} & T_{46} \\
T_{51} & T_{52} & T_{53} & T_{54} & T_{55} & T_{56} \\
T_{61} & T_{62} & T_{63} & T_{64} & T_{65} & T_{66}
\end{array}\right]\left[\begin{array}{c}
{\left[\bar{\sigma}_{z i}\right]} \\
{\left[\bar{u}_{r i}\right]} \\
{\left[u_{i i}\right]} \\
{\left[u_{z i}\right]} \\
{\left[\bar{\tau}_{r z i}\right]} \\
\left.\bar{\tau}_{\theta z i}\right]
\end{array}\right]_{z=0}
$$

Since, the top and bottom surfaces of the plate are free of static and surface forces, as a result, the normal and shear stresses are zero at these surfaces. Thus, the state-space equations for the free vibration analysis of plate can be recast to the following:

$$
\left[\begin{array}{c}
0 \\
{\left[\bar{u}_{r i}\right]} \\
{\left[u_{\theta i}\right]} \\
{\left[u_{z i}\right]} \\
0 \\
0
\end{array}\right]_{z=h_{T}}=\left[\begin{array}{llllll}
T_{11} & T_{12} & T_{13} & T_{14} & T_{15} & T_{16} \\
T_{21} & T_{22} & T_{23} & T_{24} & T_{25} & T_{26} \\
T_{31} & T_{32} & T_{33} & T_{34} & T_{35} & T_{36} \\
T_{41} & T_{42} & T_{43} & T_{44} & T_{45} & T_{46} \\
T_{51} & T_{52} & T_{53} & T_{54} & T_{55} & T_{56} \\
T_{61} & T_{62} & T_{63} & T_{64} & T_{65} & T_{66}
\end{array}\right]\left[\begin{array}{c}
0 \\
{\left[\bar{u}_{r i}\right]} \\
{\left[u_{\theta i}\right]} \\
{\left[u_{z i}\right]} \\
0 \\
0
\end{array}\right]_{z=0}
$$

Expanding the first, fifth, and sixth rows and rewriting in a matrix form, we reach to

$$
\left[\begin{array}{l}
0 \\
0 \\
0
\end{array}\right]_{z=h_{T}}=\left[\begin{array}{lll}
T_{12} & T_{13} & T_{14} \\
T_{52} & T_{53} & T_{54} \\
T_{62} & T_{63} & T_{64}
\end{array}\right]\left[\begin{array}{l}
{\left[\bar{u}_{r i}\right]} \\
{\left[u_{\theta i}\right]} \\
{\left[u_{z i}\right]}
\end{array}\right]_{z=0} .
$$

To obtain the nontrivial solution of (25), the determinant of the coefficient matrix must set to be zero, which yields a characteristic equation whose roots are the natural frequencies of the annular plate.

\section{Results and Discussions}

The type of plate considered is GLARE2 and composed of four layers [17]. The layers in the top and bottom surfaces of the plate are composed of aluminum T2024 with material properties given in Table 1. Also, the inner layers are composed of S2-glass with material properties given in Table 2.

In order to examine the convergence rate of the present analytic procedure, Table 3 lists the nondimensional natural frequencies of a clamped-clamped GLARE2 annular plate. Table 4 presents the nondimensional natural frequencies 


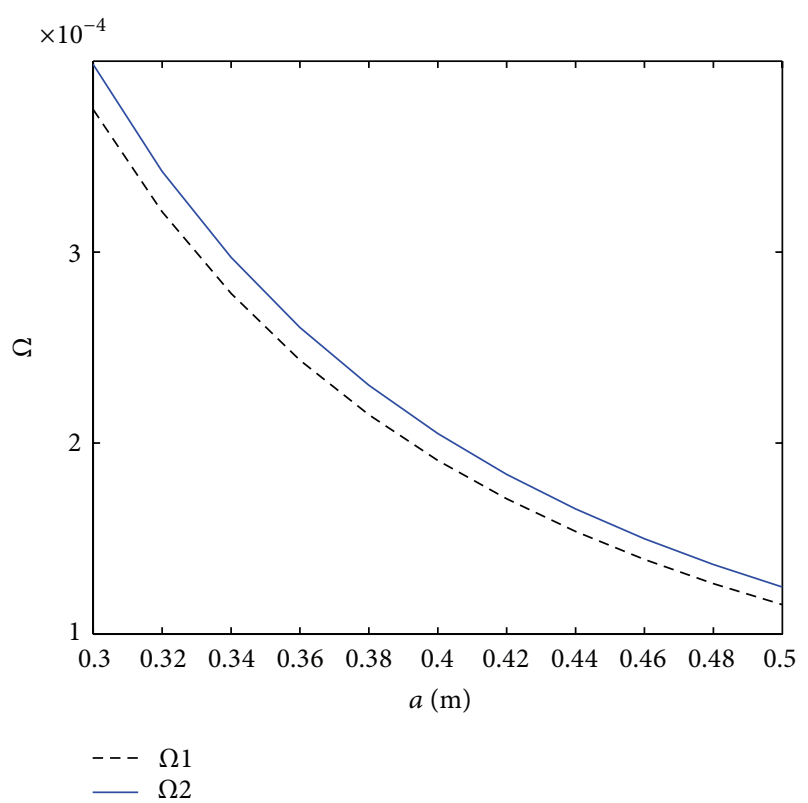

FIGURE 3: Variation of the first and second mode natural frequencies with the radius of the plate $\left(b=0.05 \mathrm{~m}\right.$ and $\left.h_{c}=0.0005 \mathrm{~m}\right)$.

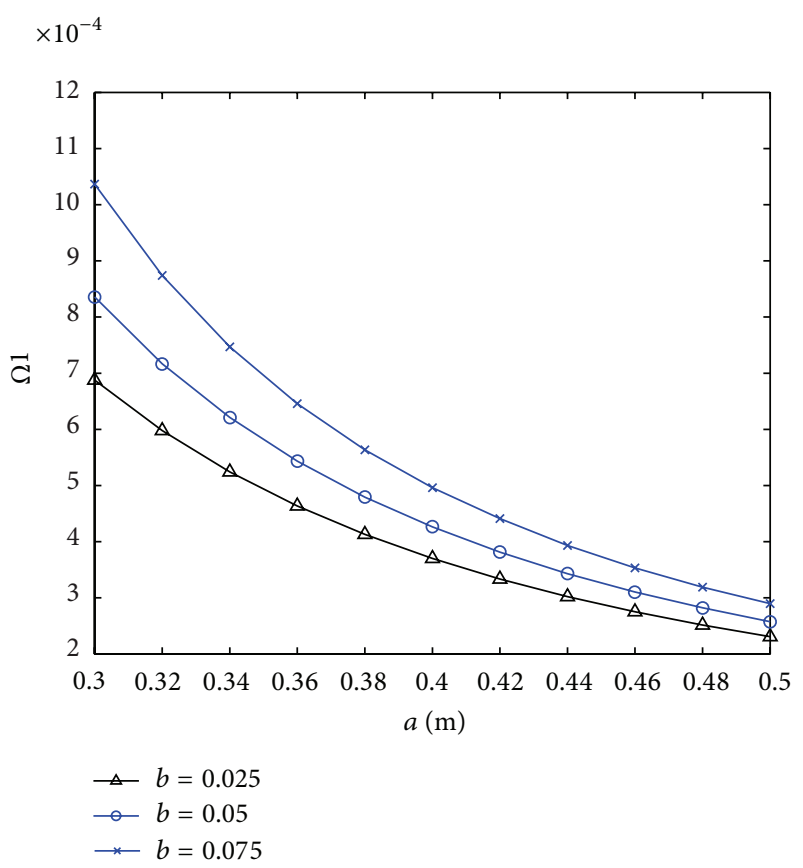

FIGURE 4: Variation of the first mode natural frequency with the radius of the plate for different hole radiuses and clamped-clamped boundary conditions $\left(h_{c}=1 \mathrm{~mm}\right)$.

associated with the first mode of vibration for a clampedclamped annular plate with different values of $h_{c}$. The top and bottom aluminum layers are assumed to be $0.5 \mathrm{~mm}$ thick. While estimating the natural frequencies, the value of $N$ is set to be equal to 11 . Results are also compared with those reported via ABAQUS software. The plate is meshed by shell-type elements. As would be observed, an excellent

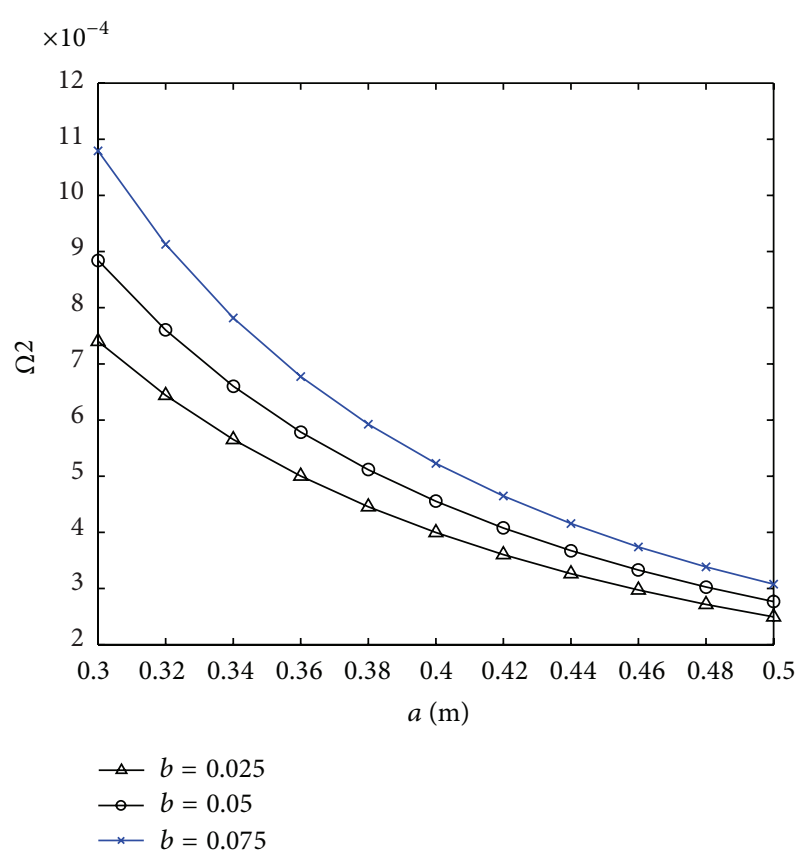

FIGURE 5: Variation of the second mode natural frequency with the radius of the plate for different hole radiuses and clamped-clamped boundary conditions $\left(h_{c}=1 \mathrm{~mm}\right)$.

TABLE 1: Mechanical properties of aluminum T2024.

\begin{tabular}{lcc}
\hline$\rho\left(\mathrm{kg} / \mathrm{m}^{3}\right)$ & $v$ & $E(\mathrm{GPa})$ \\
\hline 2780 & 0.33 & 72.2 \\
\hline
\end{tabular}

agreement has been achieved. Table 5 gives the similar results for the second mode of vibration. The first and second mode shapes of vibration for the clamped-clamped annular plate are depicted in Figure 2.

Figure 3 illustrates the variation of the natural frequencies corresponding to the first and second vibration modes with the radius of the plate having clamped-clamped end conditions. The thickness of aluminum layers on the top and bottom surfaces is taken as $0.5 \mathrm{~mm}$. The layup of composite layers is unidirectional. As can be seen from this figure the natural frequency decreases as the radius increases. This is because of the decrease in the plate stiffness. Figure 4 clarifies the variation of the natural frequency associated with the first vibration mode with the radius of the plate for different hole radiuses. Figure 5 is the similar one to the second mode of vibration. As seen from these figures, the natural frequency increases by an increment in the hole radius. This fact is mainly due to the fact that by an increase in the hole radius, the effective radius of the plate decreases and this leads to an increase in the plate stiffness and the frequency value as a consequence. Also, by increasing the radius of the hole, the mass decreases which results into an increase in the natural frequency of the plate. Figures 6 and 7 illustrate the natural frequency variations of the first and second modes with respect to the plate radius for three different thicknesses of the composite layer. As can be seen, the natural frequency 


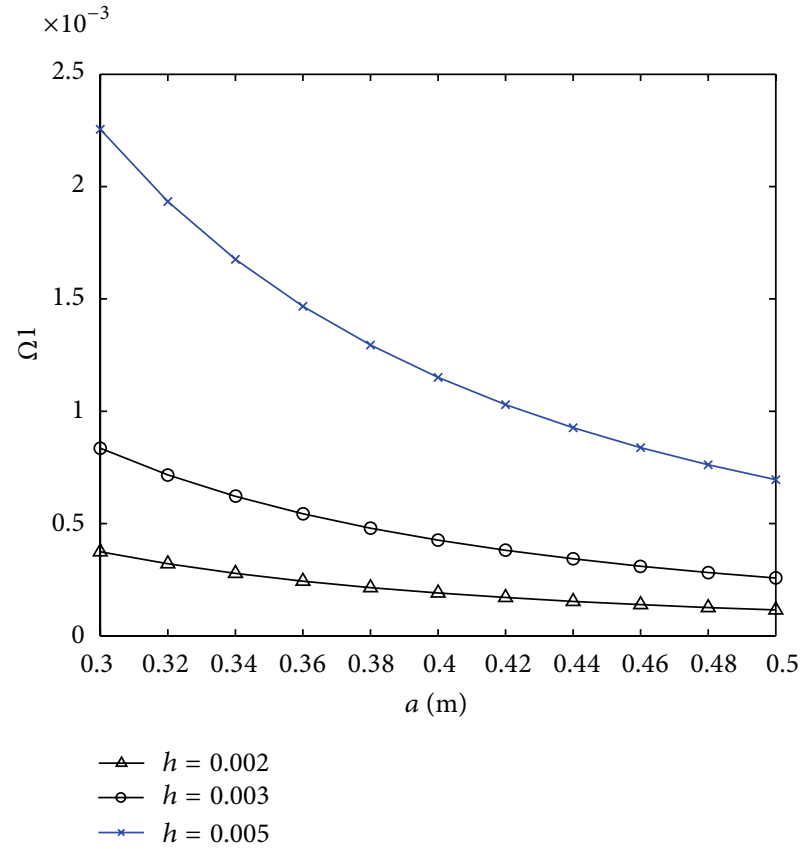

FIGURE 6: Variation of the first mode natural frequency with the radius of the plate for different composite layer thicknesses and clamped-clamped end conditions $(b=0.05 \mathrm{~m})$.

increases as the composite layer thickness increases. However, by increasing the plate thickness, the mass and stiffness values of the plate increase, but this increase is more significant for the bending stiffness.

The natural frequencies of the plate for GLARE3 are also calculated. The layup of the composite layers is considered as cross ply. Figures 8 and 9 exhibit the variation of the natural frequencies associated with the first and second vibration modes with plate radius for unidirectional and cross ply layups. The natural frequencies of plate with unidirectional layup are greater than those of the cross ply counterpart. This is because of the greatness of the bending stiffness for the unidirectional layup over the cross ply case.

Figure 10 presents the variation of natural frequencies of the first and second vibration modes for the plate with simple-simple boundary condition. Figures 11 and 12 exhibit the variations of the natural frequencies associated with the first and second vibration modes for annular plate with unidirectional layup and different boundary conditions.

\section{Conclusions}

Based on the theory of elasticity, free vibration analysis of circular fiber metal composite plate with a central hole has been performed. The governing equations derived using the elasticity theory will then be solved using a combination of differential quadrature method, state-space, and the Fourier series in order to obtain the natural frequencies of the plate. The composite metal plate is made up of GLARE and two kinds of GLARE2 and GLARE3 are chosen for the vibration analysis. Plate is composed of four layers with aluminum

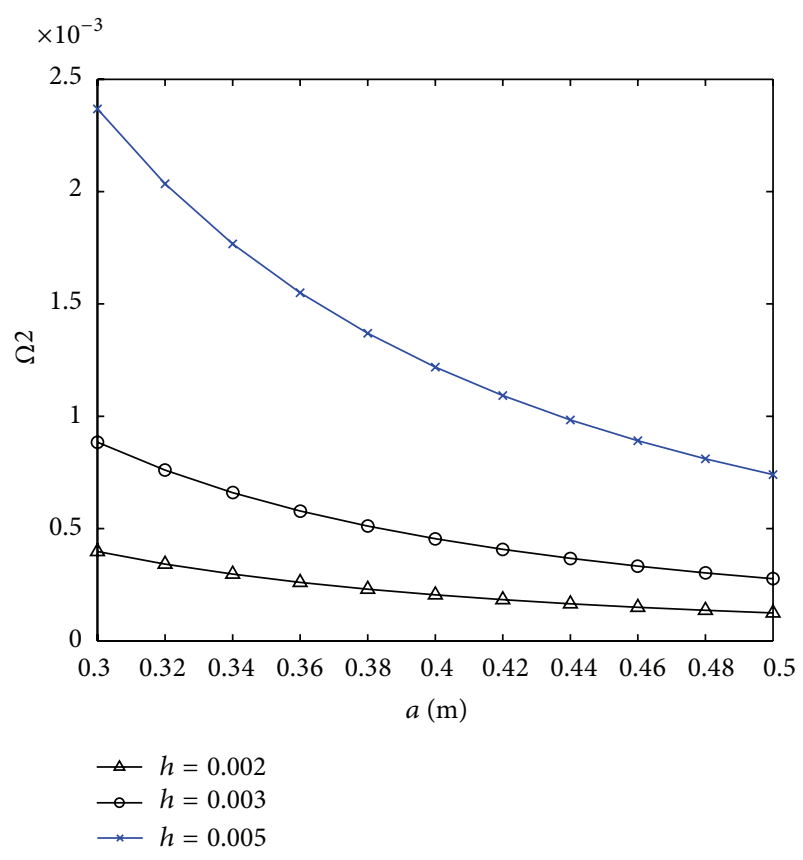

Figure 7: Variation of the second mode natural frequency with the radius of the plate for different composite layer thicknesses and clamped-clamped end conditions $(b=0.05 \mathrm{~m})$.

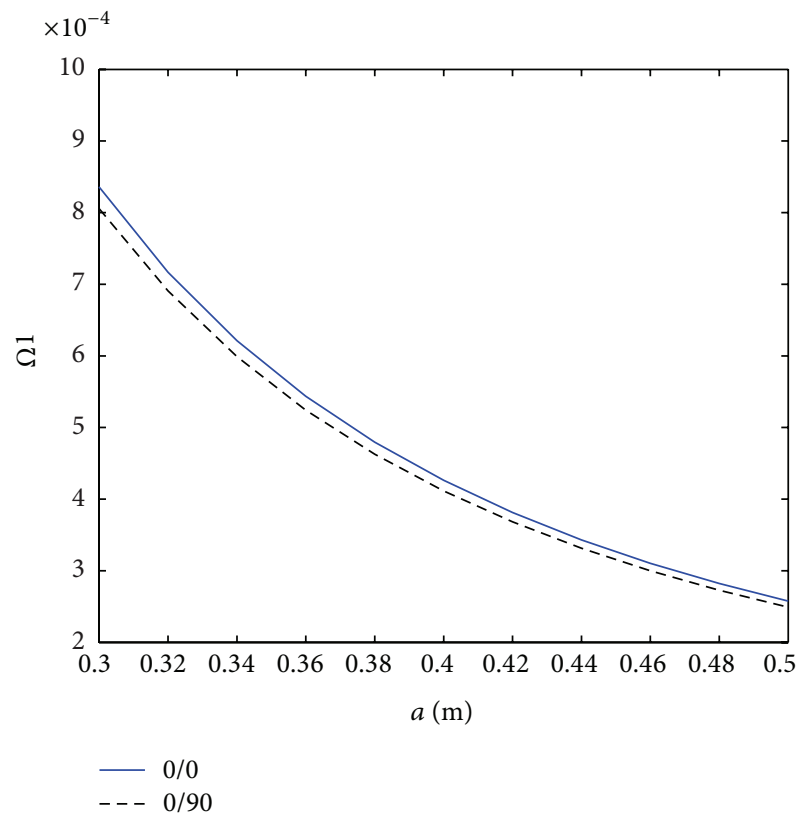

FIGURE 8: Variation of the first mode natural frequency with the radius of the plate for different layups and clamped-clamped boundary condition $\left(b=0.05 \mathrm{~m}, h_{c}=0.001 \mathrm{~m}\right)$.

layers on the top and bottom surfaces and inner composite layers. Vibration frequencies of circular fiber metal composite plates with central holes for both the clamped-clamped and simply supported boundary conditions were presented. Also, effects of layup, hole radius, and plate thickness on the natural frequencies are studied. Results obtained from present 
TABLE 2: Mechanical properties of S2-glass.

\begin{tabular}{lcccccccccc}
\hline$\rho\left(\mathrm{kg} / \mathrm{m}^{3}\right)$ & $v_{23}$ & $v_{13}$ & $v_{12}$ & $G_{23}(\mathrm{GPa})$ & $G_{12}(\mathrm{GPa})$ & $G_{13}(\mathrm{GPa})$ & $E_{33}(\mathrm{GPa})$ & $E_{22}(\mathrm{GPa})$ & $E_{11}(\mathrm{GPa})$ \\
\hline 1980 & 0.32 & 0.25 & 0.25 & 7 & 7 & 7 & 17 & 17 & 52 \\
\hline
\end{tabular}

TABLE 3: A convergence study for the nondimensional natural frequencies associated with the first and second vibration modes of a clampedclamped annular plate $(a=40 \mathrm{~cm}$ and $b=5 \mathrm{~cm})$.

\begin{tabular}{ccccccc}
\hline$m$ & $h(\mathrm{~mm})$ & $N=7$ & $N=8$ & $N=9$ & $N=10$ & 0.0001909 \\
0 & 2 & 0.0001919 & 0.0001907 & 0.0001910 & 0.0001910 \\
& 3 & 0.00042822 & 0.00042540 & 0.0004262 & 0.0004260 & 0.0004262 \\
& 5 & 0.00115613 & 0.00114870 & 0.00115090 & 0.0011502 & 0.0011508 \\
\hline & 2 & 0.0002075 & 0.0002046 & 0.0002052 & 0.0002050 & 0.0002051 \\
& 3 & 0.00046116 & 0.00045416 & 0.0004553 & 0.0004549 & 0.0004552 \\
& 5 & 0.00123097 & 0.00121644 & 0.0012193 & 0.00121824 & 0.0012190 \\
\hline
\end{tabular}

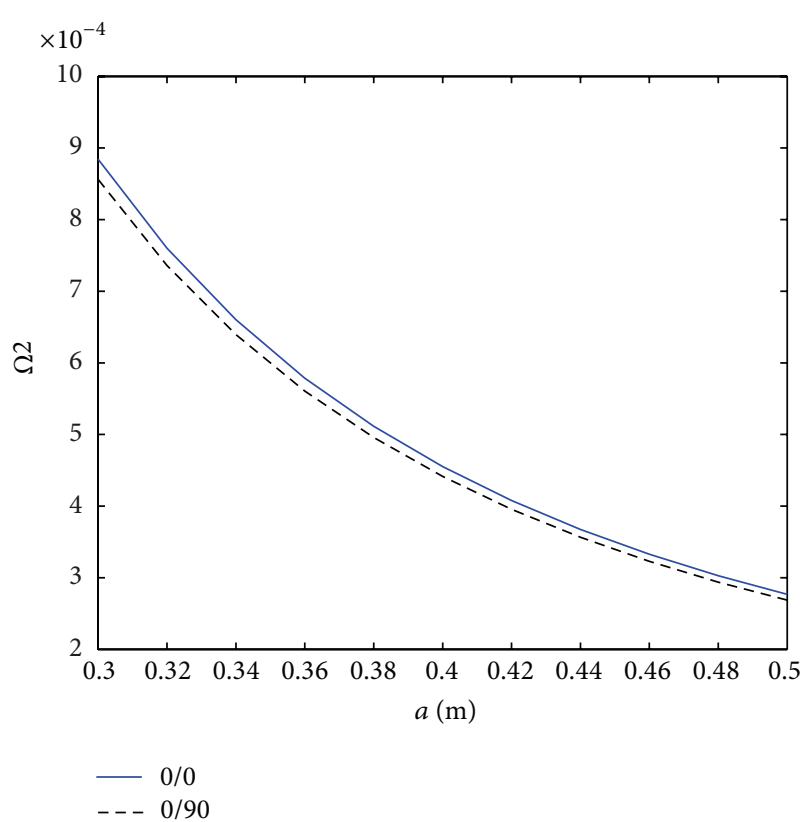

FIGURE 9: Variation of the second mode natural frequency with the radius of the plate for different layups and clamped-clamped boundary condition $\left(b=0.05 \mathrm{~m}\right.$ and $\left.h_{c}=0.001 \mathrm{~m}\right)$.

TABLE 4: Comparison of the frequency value associated with the first vibration mode for a clamped-clamped annular plate $(a=50 \mathrm{~cm}$, $b=5 \mathrm{~cm}$, and $m=0$ ).

\begin{tabular}{lccc}
\hline$h_{c}(\mathrm{~mm})$ & State-space DQM & ABAQUS & Error $(\%)$ \\
\hline 0.5 & 0.000115 & 0.0001156 & 0.5 \\
1 & 0.0002576 & 0.00025011 & 2.5 \\
2 & 0.0006955 & 0.0006415 & 8 \\
\hline
\end{tabular}

semianalytical approach have been compared with those reported by ABAQUS software. This comparison shows that the present solution is of high accuracy. The results show that the natural frequency of the plate increases with an increment

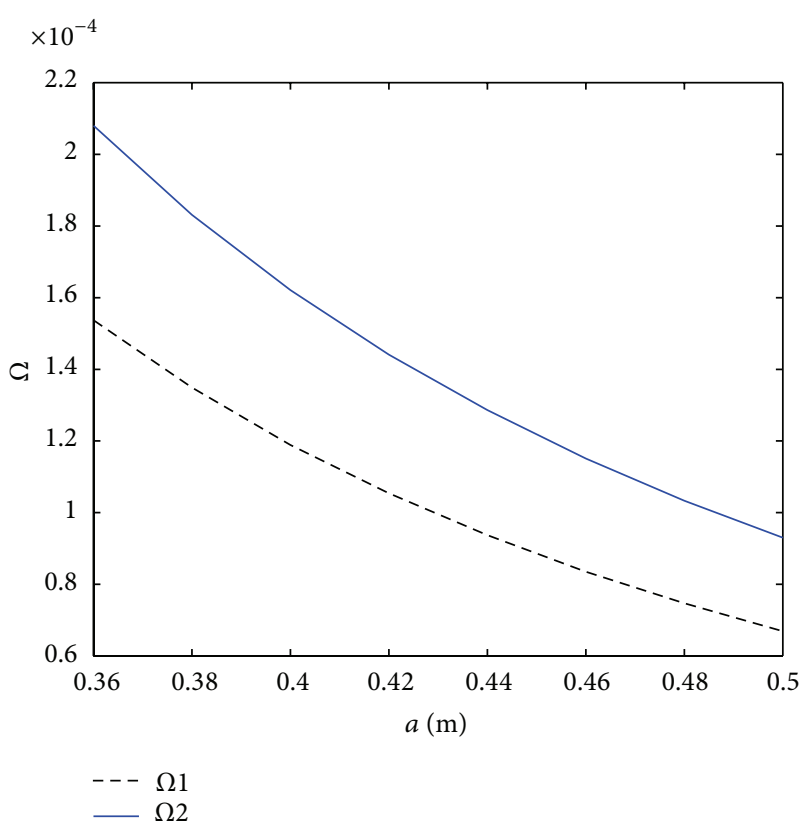

FIGURE 10: Variation of the first and second mode natural frequencies with the radius of the plate for the simple-simple boundary condition $\left(b=0.05 \mathrm{~m}\right.$ and $\left.h_{c}=0.0005 \mathrm{~m}\right)$.

TABLE 5: Comparison of the frequency value associated with the second vibration mode for a clamped-clamped annular plate $(a=$ $50 \mathrm{~cm}, b=5 \mathrm{~cm}$, and $m=1)$.

\begin{tabular}{lccc}
\hline$h_{c}(\mathrm{~mm})$ & State-space DQM & ABAQUS & Error $(\%)$ \\
\hline 0.5 & 0.0001246 & 0.0001213 & 2.6 \\
1 & 0.0002767 & 0.00025997 & 6 \\
2 & 0.0007406 & 0.00065769 & 11 \\
\hline
\end{tabular}

in the radius of the hole. This is due to the fact that the effective radius of the plate is reduced and this increases the plate stiffness and the natural frequency as a consequence. It was observed that the natural frequency of the GLARE2 


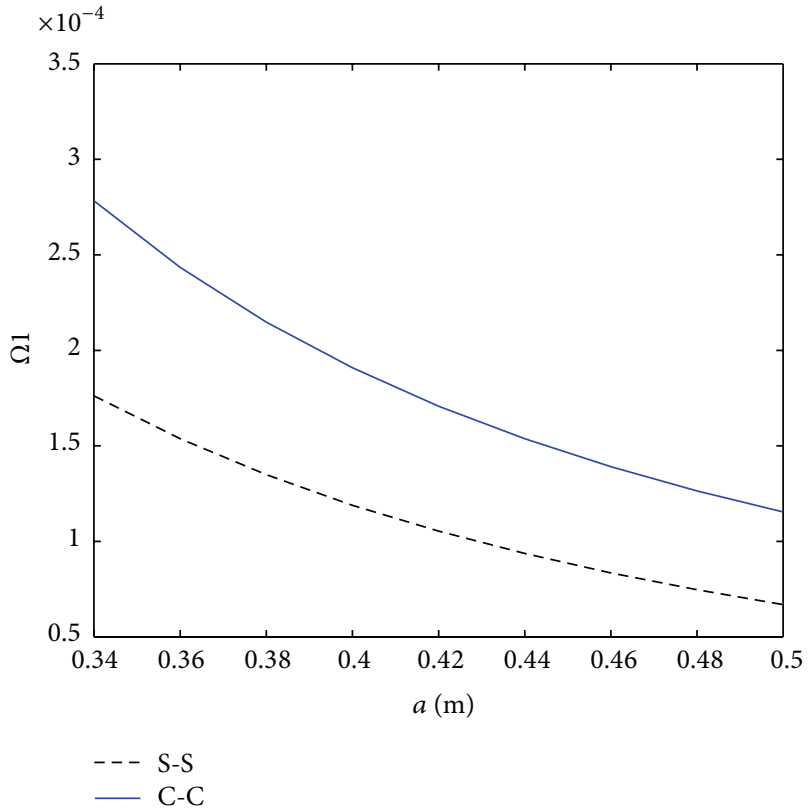

FIGURE 11: Variation of the first mode natural frequency with the radius of the plate with different boundary conditions $(b=0.05 \mathrm{~m}$ and $\left.h_{c}=0.0005 \mathrm{~m}\right)$.

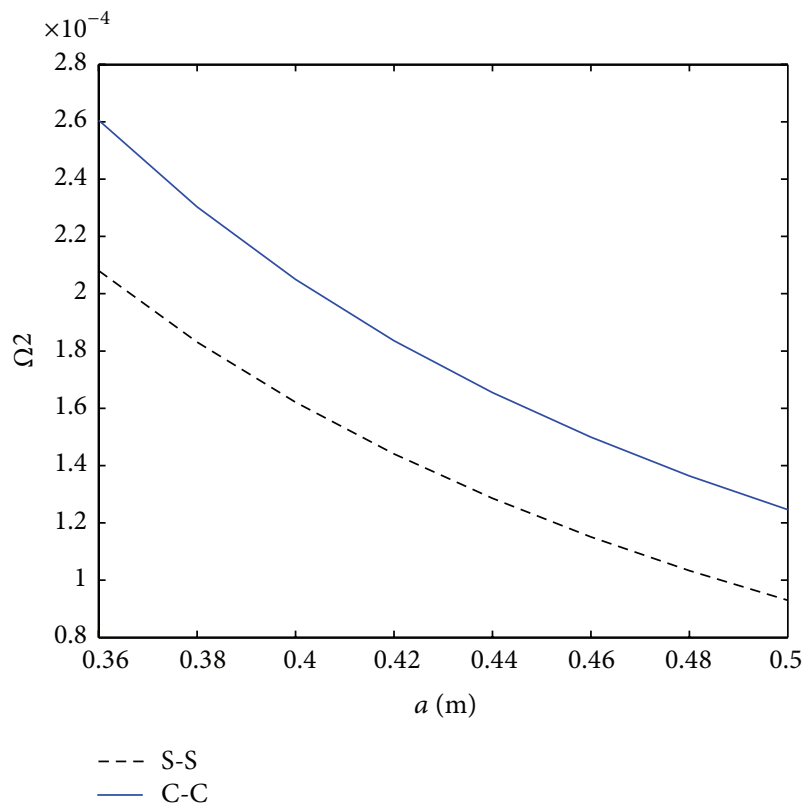

FIGURE 12: Variation of the second mode natural frequency with the radius of the plate with different boundary conditions $(b=0.05 \mathrm{~m}$ and $\left.h_{c}=0.0005 \mathrm{~m}\right)$.

for unidirectional composite layers arrangement is more compared with the GLARE3 with cross ply composite layers. Furthermore, the effect of boundary conditions on the natural frequencies was studied which illustrated that the natural frequencies of the plate with clamped-clamped boundary condition are higher than those of the simply supported case.
This is due to the fact that in the clamped-clamped case the degree of freedom is less and this causes an increase in the plate stiffness.

\section{Appendices}

\section{A. Plane Stress-Reduced Stiffnesses for the Composite Material}

$$
\begin{aligned}
& Q_{11}=m^{4} C_{11}+2 m^{2} n^{2}\left(C_{12}+2 C_{44}\right)+n^{4} Q_{22}, \\
& Q_{12}=m^{2} n^{2}\left(Q_{11}+Q_{22}-4 Q_{44}\right)+\left(m^{4}+n^{4}\right) C_{12}, \\
& Q_{13}=m^{2} C_{13}+n^{2} C_{23} \\
& Q_{14}=m n\left[\left(C_{11}-C_{12}-2 C_{44}\right) m^{2}+\left(C_{11}-C_{12}+2 C_{44}\right) n^{2}\right], \\
& Q_{22}=n^{4} C_{11}+2 m^{2} n^{2}\left(C_{12}+2 C_{44}\right)+m^{4} C_{22}, \\
& Q_{23}=m^{2} C_{23}+n^{2} C_{13} \text {, } \\
& Q_{24}=m n\left[\left(C_{11}-C_{12}-2 C_{44}\right) n^{2}+\left(C_{11}-C_{12}+2 C_{44}\right) m^{2}\right], \\
& Q_{33}=C_{33}, \\
& Q_{56}=m n\left(C_{31}-C_{32}\right) \text {, } \\
& Q_{44}=m^{2} n^{2}\left(C_{11}-2 C_{12}+C_{22}-2 C_{44}\right)+\left(m^{4}+n^{4}\right) C_{44}, \\
& Q_{55}=m^{2} C_{55}+n^{2} C_{66} \text {, } \\
& Q_{56}=m n\left(C_{55}-C_{66}\right) \text {, } \\
& Q_{66}=n^{2} C_{55}+m^{2} C_{66} \text {, }
\end{aligned}
$$

in which $m=\cos (\alpha)$ and $n=\sin (\alpha)$, where $\alpha$ is the angle between the direction of the principal axis and the fiber direction. The values of $C_{i j}$ constants only depend on the kind of material and they are given as follows:

$$
\begin{array}{ll}
C_{11}=\frac{E_{11}\left(1-v_{23} \nu_{32}\right)}{\Delta} ; & C_{12}=\frac{E_{11}\left(v_{21}+v_{31} v_{23}\right)}{\Delta} \\
C_{13}=\frac{E_{11}\left(v_{31}+v_{21} \nu_{32}\right)}{\Delta} ; & C_{22}=\frac{E_{22}\left(1-v_{31} \nu_{13}\right)}{\Delta} \\
C_{23}=\frac{E_{22}\left(v_{32}+v_{12} \nu_{13}\right)}{\Delta} ; & C_{33}=\frac{E_{33}\left(1+v_{12} v_{21}\right)}{\Delta}
\end{array}
$$




$$
\begin{gathered}
\Delta=\left(1-v_{12} v_{21}-v_{23} v_{32}-v_{13} v_{31}-2 v_{12} v_{23} \nu_{31}\right) \\
C_{44}=G_{12} \quad C_{55}=G_{13} \quad C_{66}=G_{23} .
\end{gathered}
$$

\section{B. $M$ Matrices for Different}

Boundary Conditions

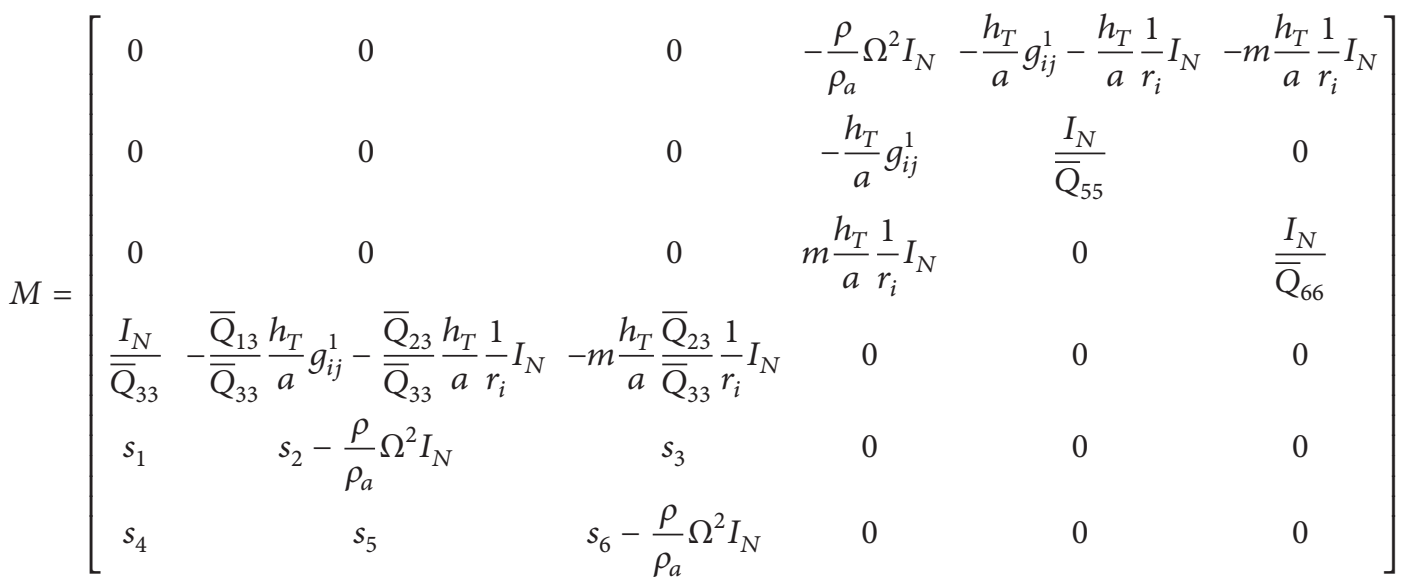

$$
\begin{aligned}
& i, j=1, \ldots, N, \\
& s_{1}=-\frac{\bar{Q}_{13}}{\bar{Q}_{33}} \frac{h_{T}}{a} g_{i j}^{1}+\frac{h_{T}}{a}\left(\frac{\bar{Q}_{23}-\bar{Q}_{13}}{\bar{Q}_{33}}\right) I_{N}, \\
& s_{2}=-\left(\frac{h_{T}}{a}\right)^{2}\left(\bar{Q}_{11}-\frac{\bar{Q}_{13}^{2}}{\bar{Q}_{33}}\right) g_{i j}^{2}+-\left(\frac{h_{T}}{a}\right)^{2}\left(\bar{Q}_{11}-\frac{\bar{Q}_{13}^{2}}{\bar{Q}_{33}}\right) \frac{1}{r_{i}} I_{N} g_{i j}^{1} \\
& +m\left(\frac{h_{T}}{a}\right)^{2}\left(m^{2} \bar{Q}_{44}+\bar{Q}_{22}-\frac{\bar{Q}_{23}^{2}}{\bar{Q}_{33}}\right) \frac{1}{r_{i}^{2}} I_{N} \\
& s_{3}=-m\left(\frac{h_{T}}{a}\right)^{2}\left(\bar{Q}_{44}+\bar{Q}_{12}-\frac{\bar{Q}_{13} \bar{Q}_{23}}{\bar{Q}_{33}}\right) \frac{1}{r_{i}} I_{N} g_{i j}^{1} \\
& +m\left(\frac{h_{T}}{a}\right)^{2}\left(\bar{Q}_{44}+\bar{Q}_{22}-\frac{\bar{Q}_{23}^{2}}{\bar{Q}_{33}}\right) \frac{1}{r_{i}^{2}} I_{N} \\
& s_{4}=m \frac{h_{T}}{a} \frac{\bar{Q}_{23}}{\bar{Q}_{33}} \frac{1}{r_{i}} I_{N} \\
& s_{5}=m\left(\frac{h_{T}}{a}\right)^{2}\left(\bar{Q}_{44}+\bar{Q}_{12}-\frac{\bar{Q}_{13} \bar{Q}_{23}}{\bar{Q}_{33}}\right) \frac{1}{r_{i}} I_{N} g_{i j}^{1}+m\left(\frac{h_{T}}{a}\right)^{2}\left(\bar{Q}_{44}+\bar{Q}_{22}-\frac{\bar{Q}_{23}^{2}}{\bar{Q}_{33}}\right) \frac{1}{r_{i}^{2}} I_{N}, \\
& s_{6}=-\left(\frac{h_{T}}{a}\right)^{2} \bar{Q}_{44} g_{i j}^{2}-\left(\frac{h_{T}}{a}\right)^{2} \bar{Q}_{44} \frac{1}{r_{i}} I_{N} g_{i j}^{1} \\
& +\left(\frac{h_{T}}{a}\right)^{2}\left(\bar{Q}_{44}+m^{2}\left(\bar{Q}_{22}-\frac{\bar{Q}_{23}^{2}}{\bar{Q}_{33}}\right)\right) \frac{1}{r_{i}^{2}} I_{N}
\end{aligned}
$$




$$
M^{C}=\left[\begin{array}{ccc}
0 & 0 & 0 \\
0 & 0 & 0 \\
0 & 0 & 0 \\
\frac{I_{N}}{\bar{Q}_{33}} & -\frac{\bar{Q}_{13}}{\bar{Q}_{33}} \frac{h_{T}}{a} g_{i j}^{1}-\frac{\bar{Q}_{23}}{\bar{Q}_{33}} \frac{h_{T}}{a} \frac{1}{r_{i}} I_{N-2} & -m \frac{h_{T}}{a} \frac{\bar{Q}_{23}}{\bar{Q}_{33}} \frac{1}{r_{i}} I_{N-2} \\
s_{1} & s_{2}-\frac{\rho}{\rho_{a}} \Omega^{2} I_{N-2} & s_{3} \\
s_{4} & s_{5} & s_{6}-\frac{\rho}{\rho_{a}} \Omega^{2} I_{N-2}
\end{array}\right.
$$$$
\left.\begin{array}{ccc}
-\frac{\rho}{\rho_{a}} \Omega^{2} I_{N-2}-\bar{Q}_{55}\left(\frac{h_{T}}{a}\right)^{2} f_{c c} & -\frac{h_{T}}{a} g_{i j}^{1}-\frac{h_{T}}{a} \frac{1}{r_{i}} I_{N-2} & -m \frac{h_{T}}{a} \frac{1}{r_{i}} I_{N-2} \\
-\frac{h_{T}}{a} g_{i j}^{1} & \frac{I_{N-2}}{\bar{Q}_{55}} & 0 \\
m \frac{h_{T}}{a} \frac{1}{r_{i}} I_{N-2} & 0 & \frac{I_{N-2}}{\bar{Q}_{66}} \\
0 & 0 & 0 \\
0 & 0 & 0 \\
0 & 0 & 0
\end{array}\right]
$$$$
f_{c c}=g_{i 1}^{1} g_{1 j}^{1}+g_{i N}^{1} g_{i j}^{1}, \quad i, j=2, \ldots, N-1 .
$$

\section{Conflict of Interests}

The authors declare that there is no conflict of interests regarding the publication of this paper.

\section{References}

[1] E. C. Botelho, A. N. Campos, E. de Barros, L. C. Pardini, and M. C. Rezende, "Damping behavior of continuous fiber/metal composite materials by the free vibration method," Composites Part $B$, vol. 37, no. 2-3, pp. 255-263, 2005.

[2] V. G. Reyes and W. J. Cantwell, "The mechanical properties of fibre-metal laminates based on glass fibre reinforced polypropylene," Composites Science and Technology, vol. 60, no. 7, pp. 10851094,2000

[3] A. Shooshtari and S. Razavi, "A closed form solution for linear and nonlinear free vibrations of composite and fiber metal laminated rectangular plates," Composite Structures, vol. 92, no. 11, pp. 2663-2675, 2010.

[4] S. M. R. Khalili, K. Malekzadeh, A. Davar, and P. Mahajan, "Dynamic response of pre-stressed fibre metal laminate (FML) circular cylindrical shells subjected to lateral pressure pulse loads," Composite Structures, vol. 92, no. 6, pp. 1308-1317, 2010.

[5] A. Alibeigloo and M. Shakeri, "Elasticity solution for the free vibration analysis of laminated cylindrical panels using the differential quadrature method," Composite Structures, vol. 81, no. 1, pp. 105-113, 2007.

[6] Y. Li and Z. Shi, "Free vibration of a functionally graded piezoelectric beam via state-space based differential quadrature," Composite Structures, vol. 87, no. 3, pp. 257-264, 2009.

[7] A. Alibeigloo and R. Madoliat, "Static analysis of cross-ply laminated plates with integrated surface piezoelectric layers using differential quadrature," Composite Structures, vol. 88, no. 3, pp. 342-353, 2009.

[8] A. Alibeigloo, "Static and vibration analysis of axi-symmetric angle-ply laminated cylindrical shell using state space differential quadrature method," International Journal of Pressure Vessels and Piping, vol. 86, no. 11, pp. 738-747, 2009.
[9] M. H. Yas and B. S. Aragh, "Free vibration analysis of continuous grading fiber reinforced plates on elastic foundation," International Journal of Engineering Science, vol. 48, no. 12, pp. 18811895, 2010.

[10] L. G. Nallim and R. O. Grossi, "Natural frequencies of symmetrically laminated elliptical and circular plates," International Journal of Mechanical Sciences, vol. 50, no. 7, pp. 1153-1167, 2008.

[11] H. R. Ovesy and J. Fazilati, "Buckling and free vibration finite strip analysis of composite plates with cutout based on two different modeling approaches," Composite Structures, vol. 94, no. 3, pp. 1250-1258, 2012.

[12] A. Baltaci, M. Sarikanat, and H. Yildiz, "Static stability of laminated composite circular plates with holes using shear deformation theory," Finite Elements in Analysis and Design, vol. 43, no. 11-12, pp. 839-846, 2007.

[13] G. J. Nie and Z. Zhong, "Semi-analytical solution for threedimensional vibration of functionally graded circular plates," Computer Methods in Applied Mechanics and Engineering, vol. 196, no. 49-52, pp. 4901-4910, 2007.

[14] R. Seifi, N. Khoda-Yari, and H. Hosseini, "Study of critical buckling loads and modes of cross-ply laminated annular plates," Composites Part B, vol. 43, no. 2, pp. 422-430, 2012.

[15] A. Jodaei, M. Jalal, and M. H. Yas, "Free vibration analysis of functionally graded annular plates by state-space based differential quadrature method and comparative modeling by ANN," Composites Part B, vol. 43, no. 2, pp. 340-353, 2012.

[16] J. N. Reddy, Mechanics of Laminated Composite Plates and Shells: Theory and Analysis, CRC Press, London, UK, 2nd edition, 2004.

[17] E. C. Botelho, R. A. Silva, L. C. Pardini, and M. C. Rezende, "A review on the development and properties of continuous fiber/epoxy/aluminum hybrid composites for aircraft structures," Materials Research, vol. 9, no. 3, pp. 247-256, 2006. 

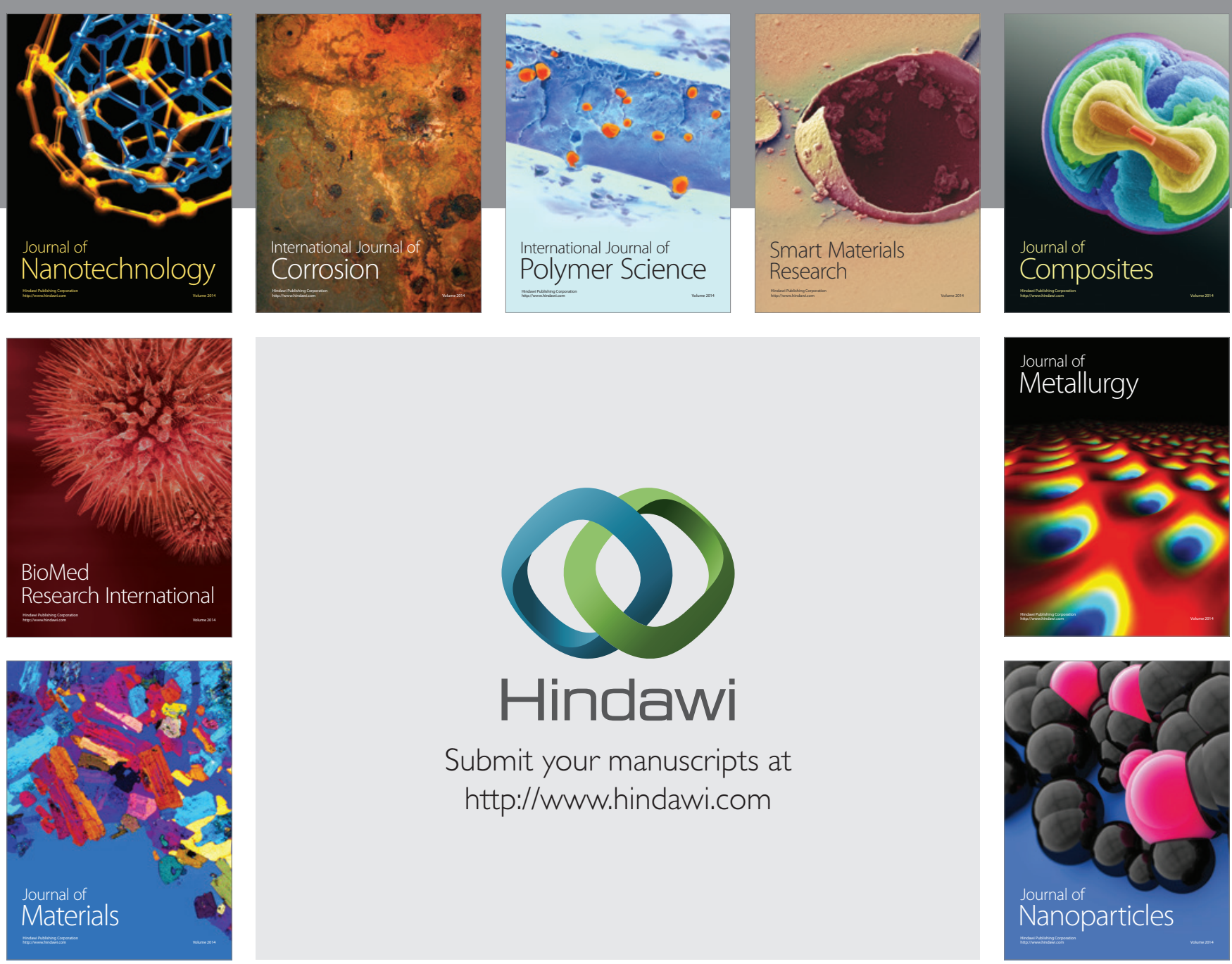

Submit your manuscripts at http://www.hindawi.com
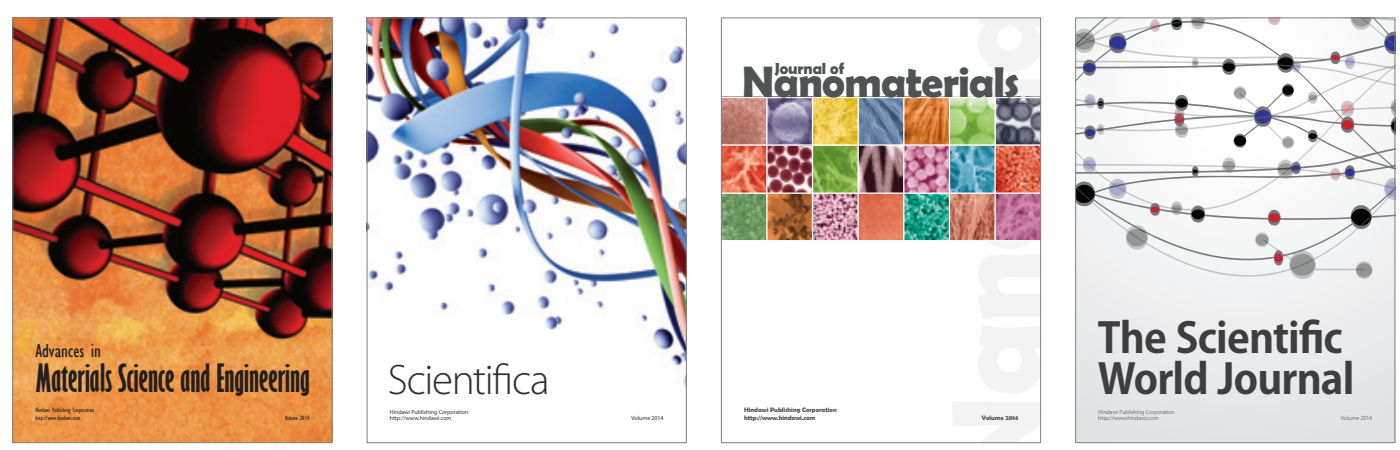

\section{The Scientific World Journal}
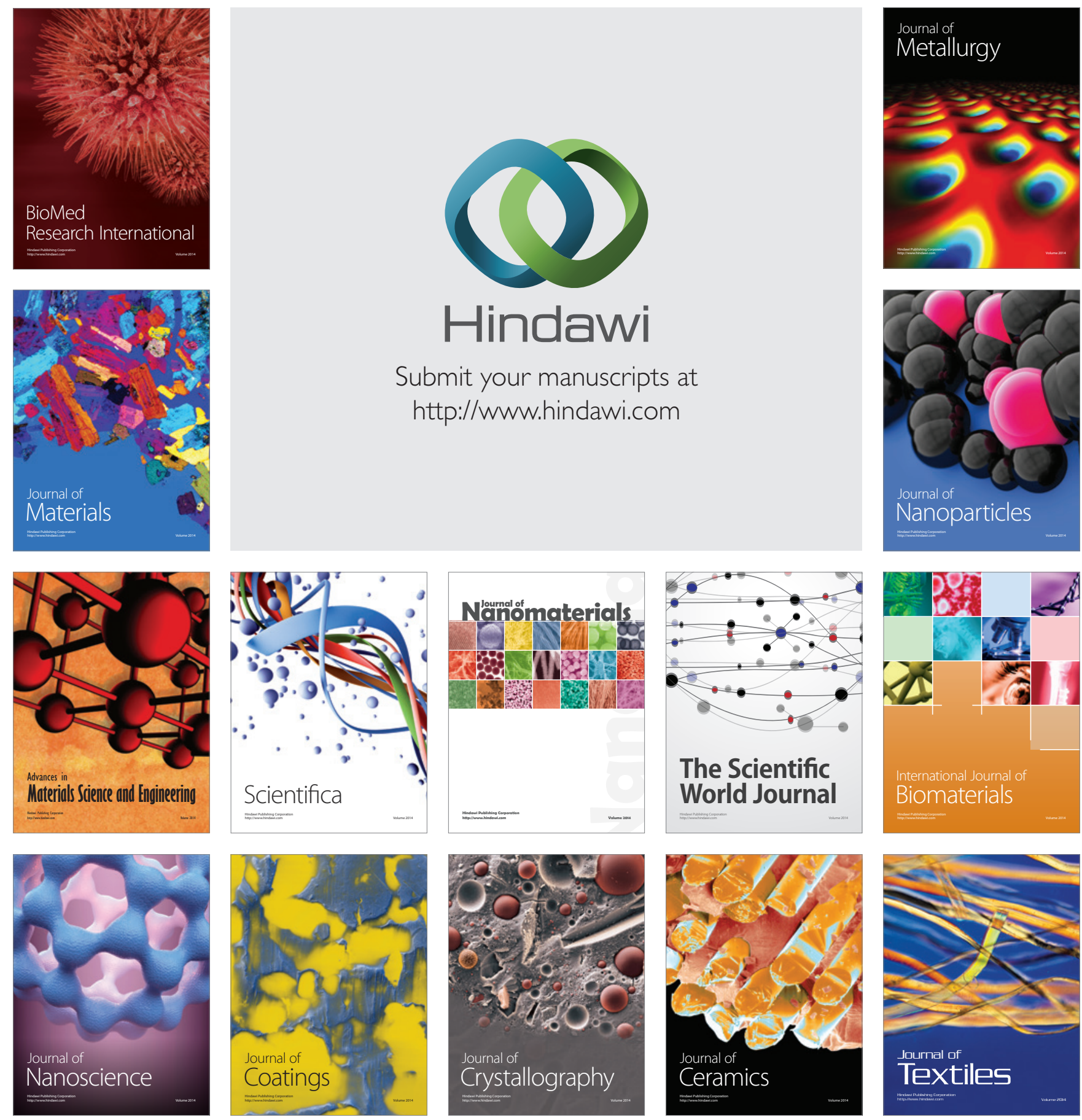